10. Liggins, M.: Premature delivery of foetal lambs infused with glucocorticoids. J.Endocrinology, 45: 515 (1969).

11. Phillips, A. F., Carson, B. S., Meschia, G. and Battaglia, F. C.: Insulin secretion in fetal and newborn sheep. Am. J. Physiol., 235: E467 (1978).

12. Steele, R., Wall, J. E., DeBodo, R. C., and Altzuler, N.: Measurement of size and turnover rate of body glucose pool by the isotopic dilution method. Am. J. Physiol, 187: 15 (1956).

13. Stern, M. P., Farguhar, J. W., Silvers, A., and Reaven, G. M.: Insulin delivery rate into plasma in normal and diabetic subjects. J. Clin. Invest., 47: 1947 (1968).

14. Willes, R. F., Boda, J. M., and Manns, J. G.: Insulin secretion by the ovine fetus in utero. Endocrinology, 84: 520 (1969).
15. We acknowledge the technical assistance of Ms. Betty Kelley and Mr. William Macomber and the secretarial assistance of Mrs. Lea Gold and Ms. Donna Perry.

16. Dr. Cowett is recipient of an RCDA, KO-4 HD-00308, NICHHD, Bethesda, MD.

17. Requests for reprints should be addressed to: Dr. William $\mathrm{OH}, 50$ Maude Street, Providence, RI 02908.

18. This research was supported in part by Major Research Programs (HD 11343) of the National Institute of Child Health and Human Development, Bethesda, MD

19. Received for publication August 10, 1982.

20. Accepted for publication February 14, 1983.

\title{
Intrarenal Distribution of Renin in the Developing Rabbit
}

\author{
ALFRED DRUKKER, ${ }^{(37)}$ VICKI S. DONOSO, MICHAEL A. LINSHAW, AND MICHAEL D. BAILIE ${ }^{(38)}$ \\ Department of Pediatrics and Kansas University Kidney and Urology Research Center, The University of Kansas \\ College of Health Sciences and Hospiral, Kansas City, Kansas, USA
}

\section{Summary}

The purpose of this study was to evaluate the intrarenal distribution of renin in individual glomerull during development in the rabbit. Superficial cortical and juxtamedullary glomeruli were obtained from animals at 1,2 , and 4 wk of age and from adults to determine renin concentration. In addition, kidney weight, total renal renin content, plasma renin concentration, and plasma anglotensin I concentration were also measured during this time period. Superficial cortical glomerular renin concentration at $1 \mathrm{wk}$ of age averaged $7.7 \pm 1.6$ (S.E.M.) $\mathrm{pg} / \mathrm{h}$ whereas juxtamedullary glomerular renin concentration was $4.5 \pm 1.8 \mathrm{pg} / \mathrm{h}$. There was no difference in concentration between the superficial and deep glomeruli at this age. At 2 wk of age, however, superficial glomerular content had increased significantly to $143.8 \pm 2.94 \mathrm{pg} / \mathrm{h}$ whereas the juxtamedullary concentration remained unchanged $(7.9 \pm 1.6$ $\mathrm{pg} / \mathrm{h})$. The concentration in the superficial nephrons continued to increase with age. At 4 wk, superficial renin content was $224.6 \pm$ 27.2 whereas the deep nephrons did not change $(16.0 \pm 7.5 \mathrm{pg} / \mathrm{h})$. Adult animals demonstrated a further increase to $842.7 \pm 15.1 \mathrm{pr}$ $\mathrm{h}$ in the superficial nephrons whereas the deep nephrons continued to remain low $(15.9 \pm 4.7 \mathrm{pg} / \mathrm{h})$.

The results of this study demonstrate that after the first week of life there was significantly more renin activity in glomerulf in the outer cortex than in the juxtamedullary cortex. Total renal renin concentration increased with age and showed a significant positive correlation with the concomitant increase in kidney weight. But renal renin content increased more than kidney weight between 1-2 wk of age.

\section{Abbreviations}

\section{AI, angiotensin I}

GRC, glomerular renin concentration

PAI, plasma angiotensin I

PRC, plasma renin concentration

RAS, renin-angiotensin system

RRC, renal renin content
The renin-angiotensin-aldosterone axis is active at birth and responds qualitatively though not quantitatively, to stimuli in a manner similar to that observed at a later age $(8,12,13,17,21,24$, 30). Relatively few data are available regarding the physiologic role of the RAS in infancy and childhood. The RAS has been implicated in the regulation of systemic and renal hemodynamics, glomerular filtration rate, glomerulotubular balance, and sodium homeostasis both in the adult animal and during development (6, $19,23,31)$. In the adult animal, the distribution of renin in the renal cortex shows a characteristic pattern. The concentration of renin is greatest in outer cortical glomeruli and far less in juxtamedullary nephrons $(3,7)$. In the immediate postnatal period, the newborn kidney undergoes rapid morphologic and functional changes; therefore, we reason that developmental change in the intrarenal distribution of renin, if present, may be important in modulating adaptive changes in neonatal renal function. The purpose of this study was to evaluate the intrarenal distribution of renin in individual glomeruli during development in the rabbit. In addition to measurement of glomerular renin content in single superficial cortical and juxtamedullary glomeruli, plasma renin concentration, plasma angiotensin I concentration, and total renin renal renin concentration were determined during development.

\section{MATERIALS AND METHODS}

Group I. Determination of PRC, PAI concentration and total $R R C$. These experiments were carried out in rabbits of the following ages: 1 day $(n=5), 3$ days $(n=5), 1$ and 2 wk $(n=4), 1$ month $(n=5)$, and adult $(n=5)$. The youngest animals were killed by decapitation; blood was collected directly into polystyrene tubes containing disodium ethylenediamenetetraacetic acid (EDTA); and the right kidney was excised. In the adult animal, blood was drawn from an ear vein while the animals were restrained in a sling and then nephrectomy was performed after anesthesia was induced with intravenous pentobarbital sodium.

Group II. Determination of renin content of single glomeruli. These experiments were performed on suckling newborn rabbits of both sexes and on adult male rabbits. Four animals were 
studied at 1 wk of age (weight $140.8 \pm 4.9 \mathrm{~g}$ ) and five animals in the other age groups: 2 wk (weight $200.4 \pm 7.8 \mathrm{~g}$ ), 4 wk (weight $746.6 \pm 13.5 \mathrm{~g}$ ), and adults (average weight $2.5 \mathrm{~kg}$ ).

Intrarenal distribution of renin in single glomeruli was determined utilizing a slight modification of the techniques described by Gilles and Morgan (11) and Granger et al. (14). This method allowed us to dissect glomeruli with the afferent arteriole and adjacent tubular structures attached and was found to be reproducible. Because renin granules are synthesized and stored in the modified muscle cells of the afferent arteriole (juxtaglomerular cells), it is important to obtain the vascular pole attached to the glomerulus for such studies.

Under pentobarbital sodium anesthesia, laparatomy was performed and the abdominal aorta cannulated with PE-50 polyethylene tubing (Clay-Adams, Inc., Parsippay, NJ). The tip of the catheter was placed at the level of the renal arteries. In very small animals, the thoracic aorta was cannulated. The aorta was clamped above or below the renal arteries and the superior mesenteric artery was tied in order to isolate the renal circulation. The renal vein was severed and the kidneys were perfused with a small amount of heparinized saline, immediately folllwed by Microfil MV-117 (Canton Biomedical Products, Inc., Boulder, CO) until the surface of the kidney turned orange. The renal arteries then were clamped and the kidneys were excised and snap-frozen in a mixture of acetone and dry ice. One kidney was freeze-dried overnight (Thermovac Industries Corporation, Copiague, Long Island, NY) and stored at $-20^{\circ} \mathrm{C}$. For microdissection of individual glomeruli, thin slices of renal cortex were cut free-hand, extending from the capsule through the cortico-medullary junction. The slices were then transferred to a petri dish, maintained at $4-10^{\circ} \mathrm{C}$, and covered with paraffin oil. The glomeruli were dissected under a Stereo Star-Zoom Microscope (American Optical Company, Buffalo, NY, Model 570; 4.2 × 25) with fine, sharply pointed needles. Thirty glomeruli were dissected from each kidney, 15 from the outermost cortical area and 15 from the corticomedullary junction. Only glomeruli with a vascular pole (afferent arterioles) attached were considered adequate for renin assay. In each experiment, the sequence of dissection was randomized, alternatively, dissecting five glomeruli from each zone. The total dissecting time averaged $1.5-2 \mathrm{~h}$ for all age groups. The glomeruli with arterioles and adjacent tubular structures were transferred in the tip of a fine glass pipet to polystyrene tubes $(12-75 \mathrm{~mm})$ for renin determination. Successful transfer of individual glomeruli was verified under the stereo-microscope for each tube. The individual glomenuli were suspended in $100 \mu$ lo $200 \mathrm{mM}$ TRIS$\mathrm{HCl}$ buffer ( $\mathrm{pH} 7.5$ ) containing $5 \mathrm{mM}$ EDTA and deep-frozen until the time of assay when the buffer was thawed and the glomeruli were homogenized by ultrasound for a period of $10 \mathrm{sec}$ at $4^{\circ} \mathrm{C}$ (Crest Ultrasnic Corp., Trenton, NJ).

Analytical techniques. Renin concentration was determined by radioimmunoassay. The generation of angiotensin I was measured in the presence of excess hog angiotensinogen. For the assay of GRC, $100 \mu$ l of this mixture was reconstituted to $100 \mu$ with 0.1 M TRIS-acetate buffer ( $\mathrm{pH}$ 7.4) containing $1 \mathrm{mg} / \mathrm{ml}$ bovine serum albumin and $2 \mathrm{mg} / \mathrm{ml}$ of neomycin. Duplicates of this mixture were incubated in polystyrene tubes at $4^{\circ} \mathrm{C}$ and $37^{\circ} \mathrm{C}$ for $4 \mathrm{~h}$ (1wk-old animals) or $2 \mathrm{~h}$ (all other age groups). The radioactivity was measured in a auto gamma-scintillation spectrophotometer (Packard Company, Model 511, Downer's Grove, IL). PRC was determined with a method described previously (34). PA I concentration was determined using the same radioimmunoassay without incubation with substrate.

RRC was determined after extraction. Briefly, tissue was homogenized with a Brinkman-Polytron homogenizer (Westbury, $\mathrm{NY}$ ) in ice cold $200 \mathrm{mM}$ TRIS-acetate buffer (pH 7.5), containing $5 \mathrm{mM}$ EDTA. The homogenate was subjected to five freeze-thaw cycles to disrupt any renin granules left intact. The homogenate was centrifuged at $3000 \mathrm{rpm}$ for $15 \mathrm{~min}$. The supernatant was dialyzed against isotonic sodium chloride at $4^{\circ} \mathrm{C}$ for $24 \mathrm{~h}$, then diluted before assay. Results were expressed as $\mathrm{ng} \mathrm{AI} / \mathrm{g}$ kidney.

Data analysis. Data for all age comparisons were analyzed by one-way analysis of variance. Where heterogeneity of variance existed, data were $\log$ transformed before analysis. Differences between experimental means were determined by the least significant difference test (32). Differences in renin content of superficial and deep glomeruli were determined using Student's $t$ test for unpaired data. The relationship between $\mathbf{R R C}$ and kidney weight was determined by linear regression analysis. In all cases, the probability level of 0.05 was used as the criterion of significance. Data are presented as mean \pm S.E.M.

\section{RESULTS}

Group I. Determination of $P R C, R R C$, and PAI. In the immediate postnatal period, PRC was not elevated and was comparable to the adult value. The value at $\mathbf{2}$ wk of age was significantly less than the adult value. Although PRC at 2 wk of age was not statistically different from that at 1 day, there was a steady decline in the values and then a rise to the adult concentration after $4 \mathrm{wk}$ of age. The result suggests that the changes in PRC are biphasic but because the values at 1-2 wk of age were not statistically lower than those at 1 day, such an interpretation requires additional studies.

PAI was highest at birth (Table 1). This value was significantly higher than values at all other ages, which did not differ from each other. Furthermore, there appeared to be no tendency toward the biphasic distribution seen with PRC. Total RRC increased with age and showed a significant positive correlation with the concomitant increase in kidney weight (Table 1, Fig. 1).

Group 2. Determination of GRC. Superficial GRC at 1 wk of age averaged $7.7 \pm 1.6 \mathrm{pg} / \mathrm{hr}$ whereas the deep GRC at this age was $4.5 \pm 1.8 \mathrm{pg} / \mathrm{h}$ (Fig. 1). During development, superficial glomerular content increased ( 2 wk, $143 \pm 2.94$; 4 wk, $224.6 \pm$ 27.3; and adult $842.7 \pm 15.1 \mathrm{pg} / \mathrm{h}$ ) but renin in the deep glomeruli did not change significantly ( $2 \mathrm{wk}, 7.9 \pm 1.6 ; 4 \mathrm{wk}, 16.0 \pm 7.5$; and adult, 15 . $\pm 4.7 \mathrm{pg} / \mathrm{h}$ ). At 1 wk of age, superficial and deep glomerular content of renin were not different. At all other ages, the glomeruli in the outer cortex contained significantly more renin activity than those in the juxtamedullary cortex. The superficial/deep GRC ratio was 1.7 at 1 wk of age, 18.2 at 2 wk, 14.0 at 4 wk of age and 52.9 in the adult animals.

Some glomeruli contained no measurable renin (Table 2). At 1 wk of age glomeruli in both the outer cortex and juxtamedullary regions of all of the kidneys had no activity. As the concentration of renin increased in the superficial cortex, the number of glomeruli containing no renin fell and almost all of the glomeruli in the outer cortex of the adult animals contained measurable quantities of renin; however, the juxtamedullar region continued to have a number of glomeruli with no activity even in the adult animals.

Table 1. Plasma renin concentration (PRC), plasma angiotensin I (PAI), total renin content (RRC) and right kidney weight in nonanesthetized rabbits 1 day of age to adulthood $(n=5)$

\begin{tabular}{|c|c|c|c|c|}
\hline Age & $\begin{array}{c}\text { PRC } \\
\text { (ngAI/ml/h) }\end{array}$ & $\begin{array}{c}\text { PAI } \\
(\mathbf{n g} / \mathbf{m l})\end{array}$ & $\begin{array}{l}\text { RRC } \\
(\mu \mathrm{g} / \mathrm{h})\end{array}$ & $\begin{array}{l}\text { Kidney } \\
\text { weight } \\
\text { (g) }\end{array}$ \\
\hline $\begin{array}{l}1 \text { day } \\
3 \text { days }\end{array}$ & & & & \\
\hline $\begin{array}{l}7 \text { days } \\
2 \text { wk } \\
4 \text { wk } \\
\text { Adult }\end{array}$ & $\begin{array}{l}0.50 \pm 0.12 \\
0.44 \pm 0.12^{2} \\
1.63 \pm 0.24^{2} \\
2.35 \pm 0.33^{3}\end{array}$ & $\begin{array}{l}0.79 \pm 0.25 \\
0.54 \pm 0.80^{2} \\
0.46 \pm 0.11^{2} \\
0.65 \pm 0.14\end{array}$ & $\begin{aligned} 40.54 & \pm 2.22 \\
88.37 & \pm 9.40 \\
147.40 & \pm 14.21 \\
284.91 & \pm 28.39\end{aligned}$ & $\begin{array}{l}0.97 \pm 0.02 \\
1.31 \pm 0.02 \\
3.82 \pm 0.14 \\
7.86 \pm 0.17\end{array}$ \\
\hline
\end{tabular}

${ }^{1}$ Mean \pm S.E.

$2 n=4$.

${ }^{3}$ Significantly higher than PRC at 2 wk of age $(P<0.05)$. All other values were not significantly different from each other.

' Significantly higher than all other PAI values $(P<0.05)$. All other values were not significantly different from each other.

${ }^{3}$ Regression analysis of relationship between increase in RRC and kidney weight with age $r^{2}=0.98 ; y=34.75 x+14.16$. 


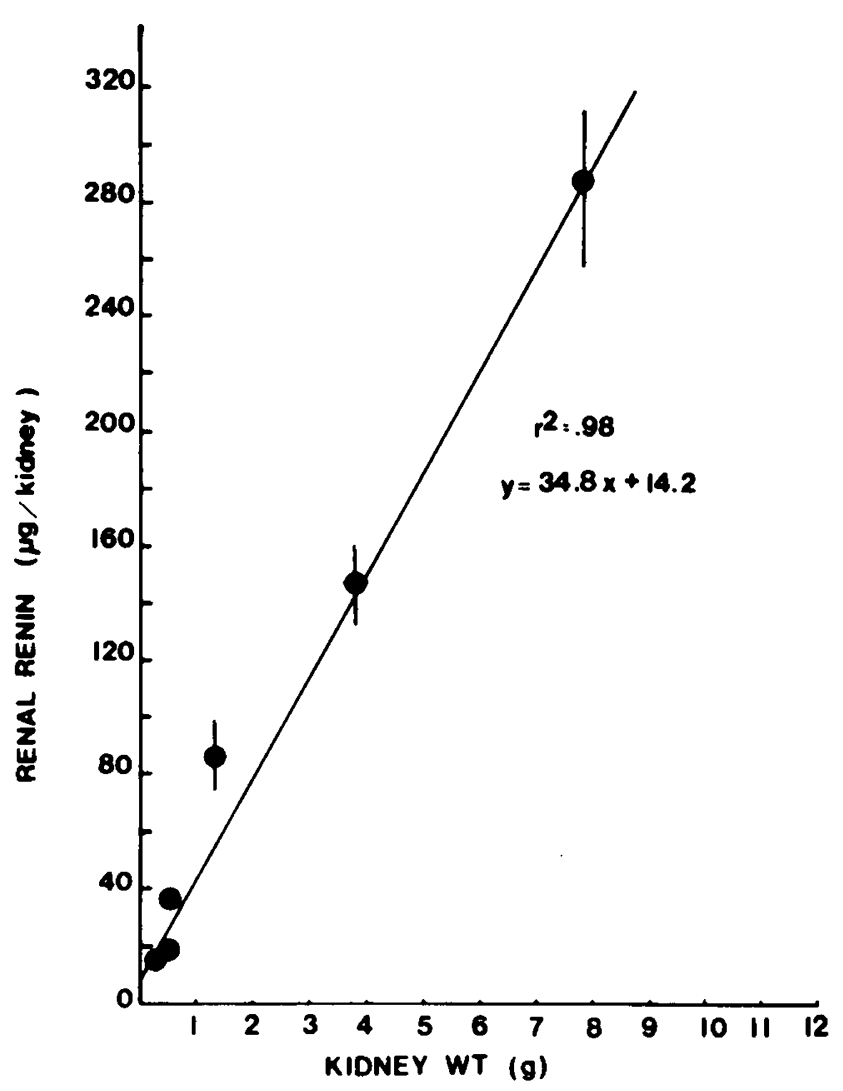

Fig. 1. Total renin content as a function of kidney weight during development. Note that at 2 wk of age (kidney weight, $131 \pm 0.02 \mathrm{~g}$ ) the increase in renal renin content is greater than the increase in kidney weight. Values are mean(s) \pm S.E.M. When S.E.M. does not appear, it falls within the units of the symbols.

Table 2. Percent of glomeruli isolated with no detectable renin

\begin{tabular}{crrrrrrrrrrr}
\hline & \multicolumn{10}{c}{ Experiment number } \\
\cline { 2 - 11 } Age & \multicolumn{1}{c}{1} & \multicolumn{1}{c}{2} & \multicolumn{2}{c}{3} & \multicolumn{1}{c}{4} & \multicolumn{2}{c}{5} \\
\hline Wk & SC $^{1}$ & JM $^{2}$ & SC & JM & SC & JM & SC & JM & SC & JM \\
1 & 40 & 27 & 40 & 47 & 27 & 20 & 60 & 85 & - & - \\
2 & 7 & 85 & 14 & 40 & 0 & 47 & 27 & 53 & 14 & 53 \\
4 & 20 & 20 & 0 & 20 & 40 & 47 & 40 & 74 & 14 & 93 \\
Adult & 0 & 50 & 0 & 60 & 0 & 14 & 7 & 47 & 7 & 47 \\
\hline
\end{tabular}

${ }^{1} \mathrm{SC}$, superficial cortical golmeruli.

${ }^{2} \mathrm{JM}$, juxtamedullary glomeruli.

\section{DISCUSSION}

The data on PRC in the developing rabbit differ from those observed in other species, including the rat, dog, piglet, lamb and human $(2,8,14,18,21,24,25,27,28,30,33)$. Plasma renin concentration in the newborn rabbit was not high and was comparable to adult values. In adult rabbits, the value was higher than that seen at 2 wk of age. There were no other statistically significant differences but there was a definite trend that may have become significant had more animals been studied. The reasons for the observed discrepancies between the present data in rabbits and those of other species is unknown. These data may indicate a different sodium handling by the rabbit pup compared to that of other species. Additional data on the renal function of rabbits during this critical period of development are needed before final conclusion can be reached.

The changes in plasma AI concentration may be, in part, related to maturation of pulmonary angiotensin I converting enzyme (34). Within 3 days after birth, the concentration of PAI had dropped significantly and remained stable throughout further development.
Previous studies have demonstrated that changes in converting enzyme may be important in the regulation of plasma concentrations of both AI and angiotensin II.

The present study shows that RRC increased rapidly after birth, a finding in accordance with that of Solomon et al. (28) and Minuth et al. (20) in developing rats and mice. In general, the increase in RRC showed a highly significant positive correlation with the increase in kidney weight; however, between 1-2 wk of age, RRC increased more than kidney weight. During that period of time, kidney weight increased by a factor of 1.35 whereas RRC rose 2.2-fold and superficial GRC increased 18-fold. During this critical period of postnatal development, there appears to be a significant absolute increase in renal renin concentration that is due to a rapid rise in outer cortical glomerular renin content. No correlation was found between RRC and PRC during development. Studies on newborn pigs suggest that PRC during development is dependent upon factors other than the release of renin from the kidney (2).

In the adult rabbit and rat, the outer cortical nephrons contain large concentrations of renin whereas the juxtamedullary nephrons contain only minimal renin activity $(3,7,11,13)$. Most studies on the intrarenal aspects of the renin-angiotensin system in fetal and early postnatal life have concentrated on morphology and few functional data are available $(4,5,9,10,20,25,26,28)$. Neogenesis of glomeruli continues in the rabbit after birth, and as in other species, development is centrifugal.

Our studies show a steep rise in renin content of the superficial glomeruli during development, the greatest increase occurring between 1-2 wk of postnatal life. From 2-4 wk of age, no significant increase in outer cortical glomerular renin content occurred. No change in renin concentration in the juxtamedullary

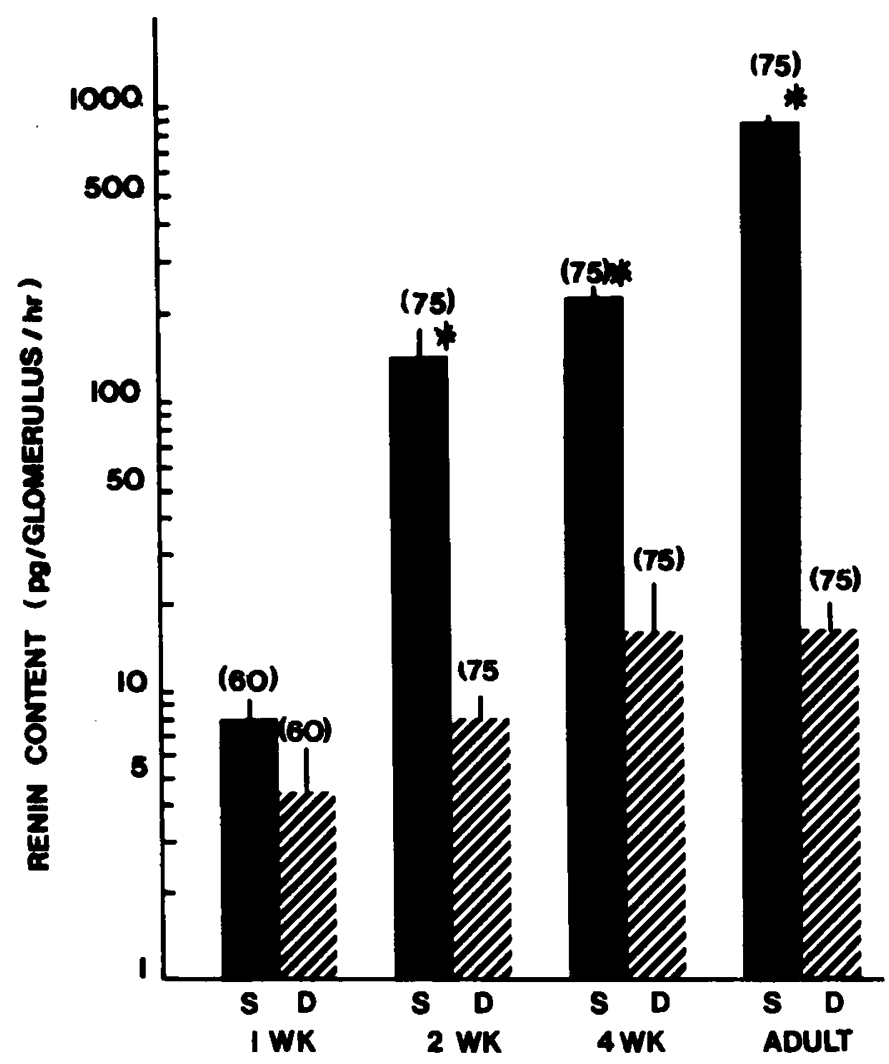

Fig. 2. Individual glomerular renin content (GRC) in the superficial $(S)$ and deep $(D)$ cortex during development. The numbers in brackets refer to the number of glomeruli assayed. At 1 wk of age, four animals, at all other ages, 5 animals were studied. Note the Log Scale on the ordinate. * Significant differences in superficial/deep GRC ratio $(P<0.05)$. Superficial GRC increased significantly from 1 wk to 2 and 4 wk of age and from 2-4 wk to adulthood. Juxtamedullary GRC did not significantly change during development $(P<0.05)$. Values are mean(s) \pm S.E. 
glomeruli was seen throughout the course of development. The adult pattern of distribution of intrarenal renin between superficial and deep glomeruli was observed from the age of 2 wk onward. Only in the youngest animals was no intrarenal renin gradient seen.

In some glomeruli, both superficial and juxtamedullary, no renin activity was measured. Brown et al. (3) also found glomeruli obtained from adult rabbit kidneys which contained no renin activity. The glomeruli with no renin were utilized in the calculation of the mean value at the various ages, because they do modify the total kidney renin content as renin appears in the glomeruli of the older animals. With maturation, fewer units with no renin were found and, in fact, in the adult animals most of the glomeruli in the superficial cortex contained renin. But there continued to be a significant number of glomeruli in the juxtamedullary regions that were without activity. This change in distribution of renin may be because the glomeruli which develop after 1-2 wk contain more renin per unit or because more renin appears in the outer cortical glomeruli, even those present at birth. Our data do suggest that the increase in total kidney renin is due to both more renin per glomerulus and less glomeruli containing no detectable renin.

Few data are available for comparison. Friedberg (10) studies the granulation of the juxtaglomerular cells of the afferent arteriole in mice during postnatal development. He found that granulation in outer cortical glomeruli increased with age. The granulation of the deep nephrons was high at birth and fell significantly over a period of 1 month after which time it remained unchanged. Thus, during the first 2 wk of life, the intrarenal pattern of granulation found in adult mice was reversed. The studies by Cain and Kraus (5) and Minuth et al. (20) also indicate that in rat and mice at birth, the juxtamedullary glomeruli contain more renin than the outer cortical nephrons. The reasons for the discrepancy between these findings and our results are not clear but may be due to species differences and/or differences in methodology. In neither of these studies was the renin content of the glomeruli determined directly.

The physiologic significance of the present findings remains unclear. In the immediate postnatal period, significant changes in renal function take place in which the RAS may play a role including an increased renal blood flow and glomerular filtration and changes in renal vascular resistance. The relatively small amount of renin found in the rabbit pup's juxtamedullary nephrons, which at birth are the most mature functioning units of the kidney, may be interpreted to suggest that renin is not important in the control of hemodynamics of these nephrons. On the other hand, the rapid increase in glomerular content of renin in the developing outer cortical nephrons may indicate a more important role for this vasopressor system in regulation of function of these units. It is of interest that the concentration of renin rises in the outer cortical nephrons in spite of the fact that at least as reported in other species, the vascular resistance decreases and renal blood flow and glomerular filtration rate increase during this period of time $(1,15,22,29)$. The elucidation of the role of the reninangiotensin system in the direct regulation of glomerular and tubular function during development will require additional information including the rate of release of renin from glomeruli and the sensitivity of the glomeruli and vasculature to angiotensin II.

\section{REFERENCES AND NOTES}

1. Arant, B. S., Jr.: Glomerulotubular balance following saline loading in the developing canine kidney. Am. J. Physiol., 235: F417 (1978).

2. Bailie, M. D., Derkx, F. H. M., and Schalekamp, M. A. D. H.: Release of active and inactive renin by the pig kidney during development. Develop. Pharmacol. Ther., 1: 47 (1980).

3. Brown, J. J., Davies, D. L., Lever, A. F., Parker, R. A., and Robertson, J. T. S The assay of renin in single glomeruli in the normal rabbit and the appearance of the juxtaglomerular apparatus. J. Physiol., 176: 418 (1965).
4. Bruehl, U., Taugner, R., and Forssmann, W. G.: Studies on the juxtaglomerular apparatus. I. Perinatal development in the rat. Cell Tiss. Res., 151: 433 (1974).

5. Cain, $H$. and Kraus, B.: Der juxtaglomerulare apparat der Rattenmere in Verlauf Von Wachstum, Reifing, and Alterung. Virchows Arch., B. Cell Pathology, 9: 164 (1971).

6. Davis, J. O. and Freeman, R. H.: Mechanisms regulating renin release. Physiol. Rev., 56: 1 (1976).

7. De Rouffignac, C., Bonvalet, J. P., and Menard, J.: Renin content in superficial and deep glomeruli of normal and salt-loaded rats. Am. J. Physiol., 226: 150 (1974).

8. Drukker, A., Goldsith, D. I., Spitzer, A., Edelmann, C. M., Jr., and Blaufox, M. D.: The renin-angiotensin system in newborn dogs: developmental patterns and response to acute saline loading. Pediatr. Res., 14: 304 (1980).

9. Eguchi, Y., Yamakawa, M., Morikawa, Y., and Hashimoto, Y.: Granular cells in the juxtaglomerular apparatus in perinatal rats. Anat. Rec., 181: 627 (1974).

10. Friedberg, E. C.: Zonal variations in the juxtaglomerular granules in mice of different ages. Nephron, 2: 230 (1965).

11. Gillies, A. and Morgan, T.: Renin content of individual juxtaglomerular apparatuses and the effect of diet, changes in nephron flow rate and in vitro acidification of the renin content. Pfluegers Arch., 375: 65 (1978).

12. Goldsmith, D. I., Drukker, A., Blaufox, M. D., Edelman, C. M., Jr., and Spitzer, A.: Hemodynamic and excretory response of the neonatal canine kidney to acute volume expansion. Am. J. Physiol., 237: F392 (1979).

13. Granger, P., Dahlheim, H., and Thurau, K.: Enzyme activities of the single juxtaglomerular apparatus in the rat kidney. Kidney Int., 1 : 78 (1972).

14. Granger, P., Rojo-Ortega, J. M., Perez, S. C., Boucher, R., and Genest, J.: The renin-angiotensin system in newborn dogs. Can. J. Physiol., Pharmacol., 49: 134 (1971).

15. Gruskin, A. B., Edelmann, C. M., Jr., and Yuan, S.: Maturational changes in renal blood flow in piglets. Pediatr. Res., 4: 7 (1970)

16. Hayduk, K., Krause, D. K., Huenges, R., and Unbehaun, V.: Plasma renin concentration at delivery and during the newborn period in humans. Experientia, 28: 1489 (1972).

17. Iwamoto, H.S. and Rudolph, A. M.: Role of renin-angiotensin system in response to hemorrhage in fetal sheep. Am. J. Physiol., 240: H848 (1981).

18. Kotchen, T. A., Strickland, A. L., Rice, T. W., and Walters, D. R.: A study of the renin-angiotensin system in newborn infants. J. Pediatr., 80: 938 (1972).

19. Leyssac, P. P.: The renin-angiotensin system and kidney function; a review of contributions to a new theory. Acta Physiol. Scan. Suppl., 442 (1976).

20. Minuth, M., Hackenthal, E., Poulsen, K., Rix, E., and Taugner, R.: Renin immunocytochemistry of the differentiating juxtaglomerular apparatus. Anat. Embryol., 162: 173 (1981).

21. Mott, J. C.: The place of the renin-angiotensin system before and after birth Brit. Med. Bull., 31: 44 (1975).

22. Olbing, H., Blaufox, M. D., Ascchinberg, L. C., Silkalns, G. I., Bernstein, J., Spitzer, A., and Edelmann, C. M., Jr.: Postnatal changes in renal glomerular blood flow distribution in puppies. J. Clin. Invest, 52: 2885 (1973).

23. Oparil, S. and Haber, E. The renin-angiotensin system. N. Engl. J. Med., 291: 389 (1974)

24. Osborn, J. L., Hook, J. B., and Bailie, M. D.: Regulation of plasma renin in developing piglets. Develop. Pharmacol. Ther., l: 217 (1980).

25. Pohlova, I. and Jelinek, J.: Components of the renin-angiotensin system in the rat during development. Pfluegers Arch., 351: 259 (1974).

26. Schmidt, D., Forssmann, W. G., and Taugner, R.: Juxtaglomerular granules of the newborn rat kidney. Pfluegers Arch., 331: 226 (1972).

27. Smith, F. G., Jr., Lupu, A. N., Bargas, L., Bauer, R. and Basore, R.: The reninangiotensin system in the fetal lamb. Pediatr. Res., 8: 611 (1974).

28. Solomon, S., Iaina, A., Eliahou, H., and Serban, I.: Postnatal changes in plasma and renal renin in the rat. Biol. Neonate, 32: 237 (1977).

29. Spitzer, A. and Brandis, M.: Functional and morphologic maturation of the superficial nephrons. J. Clin. Invest., 53: 279 (1974).

30. Sulyok, E., Varga, F., Nemeth, M., Tenyl, I., Csaba, I. F., Erti, T., and Gyorgy, E.: Furosemide-induced alterations in the electrolyte status, the function of renin-angiotensin-aldosterone system and urinary excretion of protaglandins in newborn infants. Pediatr. Res., 14: 765 (1980).

31. Spitzer, A.: The role of the kidney in sodium hemeostasis during maturation. Kidney Int., 21: 539 (1982).

32. Steel, R. G. D. and Torrie, J. H.: Principles and procedures of statistics. (McGraw Hill Co., Inc. New York 1960).

33. Trimper, C. E. and Lumbers, E. R.: The renin-angiotensin system in foetal lambs. Pfluegers Arch., 336: 1 (1972).

34. Wallace, K. B., Hook, J. B., and Bailie, M. D.: Postnatal development of the renin-angiotensin system in rats. Am. J. Physiol., 238: R432 (1980).

35. Alan Poisner, Ph.D., gracefully allowed use of his laboratory equipment.

36. The help of Lee Hong, Ph.D. with the renin assays is acknowledged.

37. Dr. Alfred Drukker performed this work during a sabbatical leave at the Department of Pediatrics, University of Kansas Medical Center. Permanent Address: Pediatric Nephrology Unit, Shaaare Zedek Medical Center, P.O. BOX 293, Jerusalem, Israel.

38. Request for reprints should be addressed to Michael D. Bailie, M.D., Ph.D., Department of Pediatrics, University Kansas Medical Center, Kansas City, Kansas 66103, U.S.A.

39. This work was supported in part by NIH Grant No. HL-22751.

40. Received for publication June 9, 1982.

41. Accepted for publication February 16, 1983. 